\title{
Using the Calculator as a Support to Generate a Meaning for Self-learning Division*
}

\author{
Elena Fabiola Ruiz Ledesma \\ IPN (Institute Polytechnic National), Mexico City, Mexico
}

\begin{abstract}
This document shows the use of the calculator to assist in solving different divisions of students in fourth grade of elementary school, through the interaction in its components (divisor, dividend, quotient and remainder). Worksheets were used with a constructivist approach, which provided the student self-assessment tests. The teacher's role was helpful when deemed necessary, in order to develop in students' self-directed learning in an environment of problem-solving and teamwork. This study used a divide-by-sides method, which was effective to understand the conventional algorithm of the division and move from the division of one number in the divisor to the double-digit divisor, without losing the sense that it involves. In the testing study, various methodological tools were used.
\end{abstract}

Keywords: autonomous learning, division, partial results and calculator

\section{Introduction}

The division algorithm with two numbers in the divisor is included in the plan and curricula to be worked in the fourth grade of elementary school (SEP (Secretary of Public Education), 1993) and is a content difficult to learn, either because they lack to diversify treatment of such problems, as Lamb and Booker (2004) registered, the origin of several problems is routine procedures that involve the sequence of actions like the "divide, multiply, subtract and down the next digit" taught in a mechanical way, without any understanding of their learning, or because students do not have the necessary background to operate the algorithm (positional value, addition, subtraction and multiplication). Another difficulty is splitting the numbers on the divisor and operating them indistinctly, as it is a single number (Saiz, 1994). Also, the fact that the students can find the result without understanding it means that there is a cognitive problem, so we set as our research problem to investigate the difficulties facing the fourth-grader elementary school students. When developing autonomous learning division with two numbers in the divisor, we proposed to use the calculator to recover the sense that the student gives the components division.

To encourage students to learn for themselves the division of two numbers on the divisor worksheets was used in a constructivist approach where they estimated and verified the result based on the reading of the problem, and participating as a team. The contents were about proportional value, the division by decomposition of the dividend and the use of the calculator. It should be noted that based on the results obtained in the initial questionnaire, it was necessary to make compensatory sessions in order to recognize and

\footnotetext{
*The author in this study was supported by IPN (Institute Polytechnic National), Number SIP: 20110343.

Elena Fabiola Ruiz Ledesma, Ph.D., researcher, Postgraduate Department, IPN (Institute Polytechnic National).
} 
reconstruct the assembling and dispersing and operate the decimal number system. Besides from the worksheets, other methodological tools were used to guide the student to get himself/herself to the canonical algorithm of division that was making their own decisions through self-assessment. The test was enriching the observed between the results of self-assessment and assessment by non-participating observers.

\section{Theoretical Framework}

We begin by mentioning Fischbein, Deri, Nello, and Marino (1985), who defined two types of division models: partitive and measure. The partitive is, "an object or collection of objects is divided into a number of identical fragments or sub-collections" (p. 7). The measure (quotient division), "seeks to determine how many times a given quantity is contained in a larger amount” (p. 7). Also, Carraher (1990, p. 216) retook the division defining it as the following way: "given the integers $A$ and $B$, exist integers $Q$ and $R$, such that $A=Q B+R$ where $0 \leq R<B$, this can be transformed in $(A-R) / B=Q$, in which $A$ is the dividend, $B$ the divisor, $Q$ the quotient and $R$ the remainder". To make the students understand the relationships between these elements, they are required to vary any of the values and assumptions of the result set (the pair ratio-residue) to check with the calculator if they did the right or not (Udina, 1992).

Also, we note that the teaching of the remainder treatment gives the possibility for students to understand the relationship among the components of the division (Galvão \& Labres, 2006), and the notion of "rest" for the student to think about the result (Saiz, 1994). It should be remembered that the result of a division with residue different from zero appears on the calculator as a number with decimal point, so the student needs to develop a strategy to find the remainder (to keep the whole number and multiply the quotient by the divisor and then subtract the product from the dividend). A different procedure to resolve the division algorithm is based on decomposing the dividend by grouping it equitably between the given quantities and it has roots in the earliest ancient Egyptians. This procedure, which we call partial results, was chosen because, among other reasons, the student does not fragment the amount of the dividend or the divisor (Carrol \& Porter, 1998).

Regarding education, we consider it from a constructivist approach as an adjusted help, through which orients the student to build their knowledge with the help of others and encourage independent learning (Becker \& Varelas, 1995; Coll \& Martin, 1999; Carter \& Fleener, 2002). Solé (1999) considered that students tend to autonomy, if, among other features, they know the criteria by which they will assess and adjust their activities. Therefore, the portfolio was included so that students valued the learning as a means of self-assessment (Aebli, 1991; Danielson \& Abrutyn, 2000), which gave meaning to the progress made by the students as their own views and opinions of others when participating in pairs or on the board, besides than the one that was given as a group during the debate, based on the written in his/her diary (Flückiger, 2005).

\section{Methodology}

During the first school year, we worked with public fourth grade elementary school students in afternoon shift, which showed an adequate performance in school, which is qualitative and in the form of participant observation where the observer-researcher is involved in the same activities. Also, at the end of the session, we took notes of the features related to the problem of research to reflect on the relevance of them.

\section{Stage and Subject}

We worked with 18 students of fourth grade elementary school (between ten and 12 years old), who had good school performance expressed through the results of the national assessment for academic achievement in 
schools of the Ministry of Public Education. This group was chosen because of the reflection and self-regulation of learning needs of students who have appropriate levels to ensure understanding and mastery of the background needed for division problems-solving of two numbers in the divisor. Also, each student had a calculator to solve the work sheets where requested the use of it. The primary is located in Mexico City and most parents had completed junior high education and engaged in activities organized on campus. Socioeconomic status of the population is different, because it comes from different economic activities.

\section{Methodological Tools}

Two questionnaires were applied, one initial and the other final, which had the same tasks, in order to compare the responses of students regarding the decimal numbering system and the four fundamental operations (evaluation by the investigator). Based on the initial questionnaire, there was the need of compensatory activities to understand and reconstruct the decimal number system. To promote independent learning of division of the student, we developed a constructivist teaching intervention which relied on the use of 15 worksheets, used in many teaching sessions. These cards were solved individually or in pairs in order to appear as a workgroup. After each card, the student wrote in his/her diary a reflection on the contents worked (what he/she learned and the difficulties he had) and had arguments for the debate.

The self-evaluation was carried out by a portfolio, which contains the worksheets and reflections that each student did. Also, on three occasions, two non-participating observers registered (quantitatively and qualitatively) in a guide what happened during the session. In the end, an interview was applied to three students of different performance (high, medium and low) to clarify some doubts about the answers to their worksheets.

\section{Validation Procedures}

Two validation strategies were used: cross-checking and triangulation. Cross checks were established with two non-participating observers who recorded what happened in five sessions of instruction and for triangulation, it was mixed, comparing data from the worksheets, questionnaires and annotations the students wrote in their portfolio and interviews.

\section{Categories of Analysis}

This qualitative study analyzed the results of the worksheets where the calculator was used as support for rescue: (1) the sense of the division through the residue; and (2) the relationship between dividend-divisor and quotient-remainder.

\section{Preliminary Analysis of Results}

Of the pilot study, worksheets were selected some results that have not been reported in other investigations. In the "Calculator" card, students are asked to solve two problems with their calculator and find what cannot be distributed.

\section{The First Problem}

Ana will put chocolates on 457 packs. If each packet must carry 24 chocolates, how many packages will she use? How many chocolates are loose? Explain your answer.

Nine students (9/18) generated sense, which was shown in the graphic representation presented. Of the nine, four of them were divided with the calculator $457 \div 24$ and re-used to multiply the quotient by the divisor and subtract the product of the dividend (see Figures 1 and 2). 


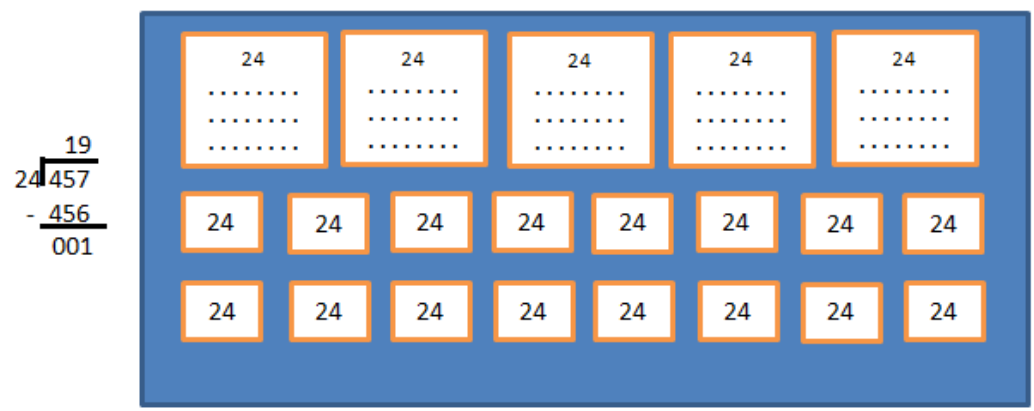

Figure 1. Representation of the first problem.

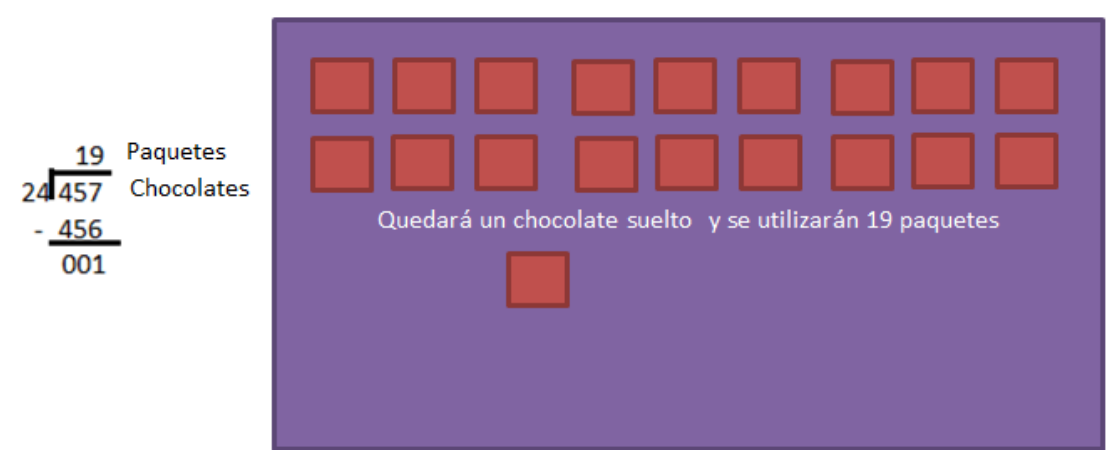

Figure 2. Representation.

\section{The Second Problem}

Lilith bought three dresses with credit at $\$ 675$. If she has to give $\$ 60$ weekly, how many weeks will take her to pay the $\$ 675$ ? How much will the final payment be? Explain your answer.

Three $(3 / 18)$ of the 18 students used the calculator, found $675 \div 60$ and wrote only the results (11 and 15$)$ (see Figure 3).

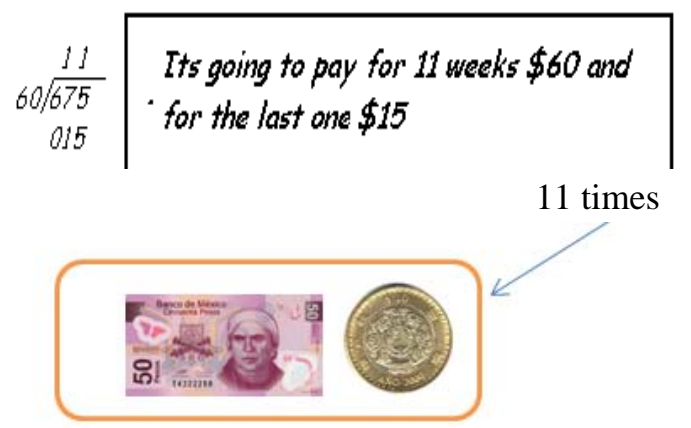

Figure 3. Representartion of the second problem.

On the card, "All we hike" means that they had to create the problem by considering the residual: Several schools came together for hiking. If there are 698 people and trucks will be hired with room for 32 people, how many trucks are contracted to tour with them all? Only two students $(2 / 18)$ solved it properly. Here is the procedure of "partial results" (see Figure 4).

Another problem was: If we have 59 apples to distribute in five boxes and each box we get the same amount, how many apples go in each box? How many remain given out? In the Figure 5, it shows the procedure of "partial results". 


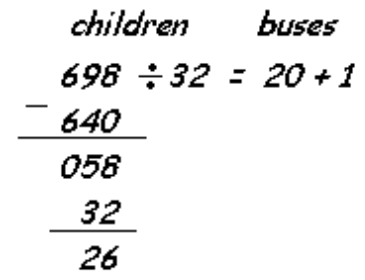

22 buses hired

Figure 4. Procedure of "partial results".

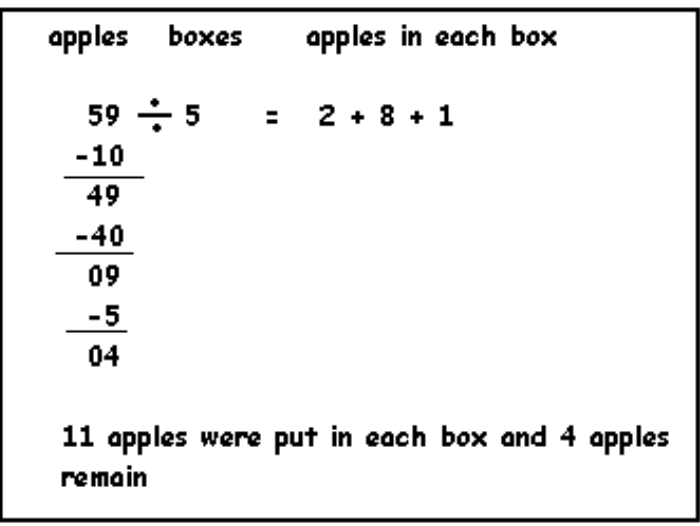

Figure 5. Procedure of "partial results".

"inaking no operations"

*If we have give out $\$ 595$ between 35 persons and everyone must hawe the same. How much will have every person? Explain.

a) between $\$ 5$ and $\$ 9$ bjbetween $\$ 10$ and $\$ 20$ cjbetween $\$ 30$ and $\$ 40$

Because i made a mental opration

Check it with the calculator, was it right? Yes

*If we have the same $\$ 595$ but instead of 35 persons now we have 15 persons to giwe out in same parts. What do you thing would happen?

a) they will get less money b) they will get more money

Because to 35 people each one have 17 now if they are less, must have more

Check it with the calculator, was it right? Yes

*Now if we increase $\$ 140$ to $\$ 595$ and we equally distribute between the 35 persons. What will happen?

a) they will get less money bj they will get mone money

Becouse now its $\$ 140$ more

Check it with the calculator", was it right? Yes

Figure 6. Questionnaire resolution. 
The procedure of "partial results" consists of the following: Write the dividend and the divisor in the order they are read. The student began by choosing a number and placed after the equal sign, which is multiplied by the divisor and the dividend is subtracted product to make a way for a partial remainder, this approach continues (by placing a plus sign between each number chosen) until the partial remainder is less than the divisor.

In another worksheet, the students were asked to used the calculator to check their answers. We found that most students (15/18) correctly solved the tab, which is shown in Figure 6.

\section{Conclusions}

The use of calculator supports the student to find the partner's result quotient residue but must be linked to the plot, since the explanation with the calculator helps students to make sense of spread or grouping. A few students (2/18) solved the problem giving meaning to "the excess" due to re-read the problem and realized all the underlined word. The solving of various tasks of the cards through individual work, teamwork and group support the student learning division through their own skills with the help of colleagues. Activities in pairs encourage greater involvement of students.

\section{References}

Aebli, H. (1991). Learning to learn (pp. 151-175). In Teaching factors that help the autodidactic learning. Madrid: Narcea.

Becker, J., \& Varelas, M. (1995). Assisting construction: The role of the teacher in assisting the learner's construction of preexisting cultural knowledge (pp. 433-446). In L. Steffe, \& J. Gale (Eds.), Constructivism in education. Hillsdale, New Jersey: Lawrence Erlbaum Associates.

Carraher, D. W. (1990). Understanding the division: Algorithm from new perspectives (pp. 215-222). In Proceeding of the 14th National Board of Science and Technology. Government of The State of Morelos, IBM Mexico and Educative Mathematics of the Research Centre and Advanced Studies of the IPN.

Carrol, W., \& Porter, D. (1998). Alternative algorithms for whole-number operations (pp. 106-114). In L. J. Morrow, \& M. J. Kenney (Eds.), The teaching and learning of algorithms in school mathematics. USA: The National Council of Teachers of Mathematics.

Carter, A., \& Fleener, M. (2002). Exploring the teacher’s role in developing autonomy (pp. 819-829). In D. Mewborn, P. Sztajn, D. White, H. Wiegel, R. Bryant, \& K. Nooney (Eds.), Proceedings of the Twenty-Fourth Annual Meeting: North American Chapter of the International Group for the Psychology of Mathematics Education (Vol. 2). Columbus, O. H.: Clearinghouse on Science, Mathematics and Environmental Education.

Coll, C., \& Martín, E. (1999). Evaluation of the learning in the scholar curricula: A constructivist perspective. In The constructivism in the classroom (pp. 163-183). Barcelona: Graó.

Danielson, C., \& Abrutyn, L. (2000). Introduction to the learning evidence inside the classroom. México: Fondo de Cultura Económica.

Fischbein, E., Deri, M., Nello, M., \& Marino, M. (1985). The role of implicit models in solving verbal problems in multiplication and division. Journal for Research in Mathematics Education, 16(1), 3-17. Georgia: The National Council of Teachers of Mathematics.

Flückiger, A. (2005). Macro-situation and numerical knowledge building: The role of pupils' didactic memory in classroom interactions. Educational Studies in Mathematics, 59, 59-84. Dordrecht: Kluwer Academic.

Galvão, A., \& Labres, S. (2006). Exploring the role played by the remainder in the solution of division problems (pp. 153-160). In J. Novotná, H. Moraová, M. Krátká, \& N. Stehlíková (Eds.), Proceedings of 30th Conference of the International Group for the Psychology of Mathematics Education (Vol. 5). Prague: Federal University of Pernambuco.

Lamb, J., \& Booker, G. (2004). The impact of developing teacher conceptual knowledge on students' knowledge of division (pp. 177-184). In M. Johnsen Hornes, \& A. Berit Fuglestad (Eds.), Proceedings of the 28th Conference of the International Group for the Psychology of Mathematics Education (Vol. 3). Bergen, Norway: Bergen University College.

Saiz, I. (1994). Division difficulties or difficulties to divide (pp. 185-215). In C. Parra, \& H. Weissmann (Eds.), Didactic of the mathematics: Reflections and contributions. Barcelona: Paidós.

SEP (Secretary of Public Education). (1993). Plan and study programs 1993: Basic education: Primary. México: Secretaría de Educación Pública.

Solé, I. (1999). Availability to the learning and the sense of learning. In The constructivism in the classroom (pp. 25-46). Barcelona: Graó.

Udina, F. (1992). Aritmetic and calculator (Vol. 10). España: Síntesis. 